\title{
Thyroid Gland Squamous Cell Carcinoma
}

National Cancer Institute

\section{Source}

National Cancer Institute. Thyroid Gland Squamous Cell Carcinoma. NCI Thesaurus. Code C46008.

A rapidly growing primary carcinoma of the thyroid gland composed of malignant squamous cells. The clinical course is usually aggressive. 